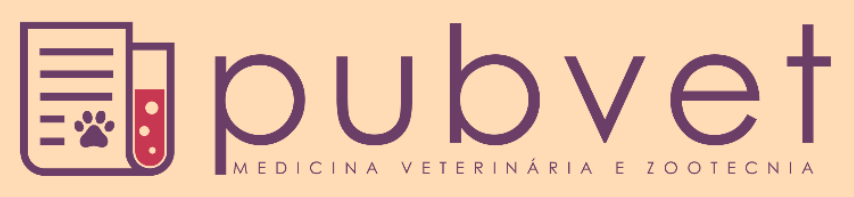

ISSN $1982-1263$

https://doi.org/10.31533/pubvet.v14n1a486.1-6

\title{
Lupus eritematoso discoide em cão: relato de caso
}

\author{
Juliana Furtado Lima-Verde ${ }^{\ominus}$, Tiago Cunha Ferreira ${ }^{2 *} \bullet$, Diana Célia Sousa Nunes-Pinheiro ${ }^{3} \bullet$ \\ ${ }^{1}$ Programa de Pós-Graduação em Ciências Veterinárias, Universidade Estadual do Ceará. Fortaleza-CE Brasil. \\ ${ }^{2}$ Docente da Universidade Estadual do Ceará, Faculdade de Veterinária. Fortaleza-CE Brasil. \\ ${ }^{3}$ Docente do Programa de Pós-Graduação em Ciências Veterinárias da Universidade Estadual do Ceará, Faculdade de Veterinária. Fortaleza-CE Brasil. \\ *Autor para correspondência, E-mail: tiago.cunha@uece.br
}

Resumo. O objetivo do presente trabalho é relatar um caso de clínico de lúpus eritematoso discoide (LED) canino. Um cão da raça akita, cinco anos de idade, com histórico de intenso prurido e lesões crostosas nas regiões periocular, nasal e membros foi atendido em serviço clínico especializado. Testes sorológicos para Erliquiose, Babesiose e Leishmaniose Canina foram negativos, e os exames hemato-bioquímicos estavam dentro dos padrões de normalidade para a espécie. Dermatite de interface e liquenoide foram observadas em fragmentos de biópsia, enquanto, células descamativas e inflamatórias estavam presentes em citologia por imprint cutâneo. Esses dados colaboram para um diagnóstico de LED. Vale ressaltar ausência de adeno, hepato e esplenomegalias e de alterações em sistemas locomotor e renal aos exames ultrassonográfico e clínico. A doença foi responsiva ao uso de mometasona tópica e prednisolona sistêmica, pentoxifilina e suplementação com vitamina $\mathrm{E}$, as quais forneceram melhora do quadro clínico a partir de sete dias de tratamento.

Palavras chave: Autoimunidade, dermatite de interface, dermatologia canina, drogas imunomoduladoras, predisposição genética

\section{Discoid lupus erythematosus in dog: case report}

\begin{abstract}
The aim of the present study is to report a case of canine discoid lupus erythematosus (DLE). A five-year-old Akita dog with a history of severe itching and crusted lesions in the periocular, nasal and limb regions was treated at a specialized clinical service. Serological tests for erlichiosis, babesiosis and canine leishmaniasis were negative, and the blood-biochemical tests were within normal limits for the species. Interface dermatitis and lichenoid were observed in biopsy fragments, while scaling and inflammatory cells were present in skin cytology. This data contributes to a DLE diagnosis. It is worth mentioning the absence of adeno, hepato and splenomegalies and alterations in the locomotor and renal systems at ultrasound and clinical examinations. The disease was responsive to the use of topical mometasone and systemic prednisolone, pentoxifylline and vitamin $\mathrm{E}$ supplementation, which provided clinical improvement after seven days of treatment.
\end{abstract}

Keywords: Autoimmunity, interface dermatitis, canine dermatology, immunomodulatory drugs, genetic predisposition

\section{Lupus eritematoso discoide en perro: reporte de un caso}

Resumen. El objetivo del presente estudio es informar un caso clínico de lupus eritematoso discoide canino (LED). Un perro Akita de cinco años con antecedentes de picazón severa y lesiones con costras en las regiones periocular, nasal y de las extremidades fue tratado en un servicio clínico especializado. Las pruebas serológicas para erliquiosis, babesiosis y leishmaniasis canina fueron negativas, y las pruebas hemato-bioquímicas estuvieron dentro de los límites normales para la especie. Se observaron dermatitis de interfaz y liquenoide en 
fragmentos de biopsia, mientras que las células inflamatorias y escamosas estaban presentes en la citología por imprint cutáneo. Estos datos contribuyen a un diagnóstico de LED. Vale la pena mencionar la ausencia de adeno, hepato y esplenomegalias y alteraciones en los sistemas locomotor y renal en la ecografía y los exámenes clínicos. La enfermedad fue sensible al uso de mometasona tópica y prednisolona sistémica, pentoxifilina y suplementos de vitamina $\mathrm{E}$, que proporcionaron una mejoría clínica después de siete días de tratamiento.

Palabras clave: Autoinmunidad, dermatitis de interfaz, dermatología canina, fármacos inmunomoduladores, predisposición genética

\section{Introdução}

A dermatologia veterinária é uma especialidade que está em constante crescimento na clínica médica de pequenos animais (Pinho et al., 2015). Dentre as dermatopatias, as autoimunes, embora raras, representam de 2 a $5 \%$ da casuística dos atendimentos e têm importância devido ao difícil diagnóstico e similaridade clínica com outras doenças tegumentares (Larsson \& Lucas, 2019).

As dermatopatias autoimunes são patologias provocadas por uma orientação desordenada do sistema imunológico dos pacientes acometidos, causando uma reação incomum e anormal contra componentes do seu próprio organismo (Wang et al., 2015). Embora possuam diferentes etiologias, o desenvolvimento de tais doenças pode ser influenciado por fatores ambientais, como radiação ultravioleta e uso de medicamentos (Ferreira et al., 2019; Larsson \& Lucas, 2019). O lupus eritematoso discoide (LED) canino pertence ao grupo das doenças autoimunes, sendo sua etiopatogenina ainda incerta. Contudo, sabe-se que as lesões lúpicas podem ser iniciadas após exposição a raios UVA e UVB que induzem lesão aos queratinócitos, provocando infiltração de linfócitos e produção de autoanticorpos reativos, culminando com o desencadeamento de mecanismos citotóxicos e deposição de imunocomplexos com ativação do sistema complemento (Hejazi \& Werth, 2016).

O LED apresenta-se, clinicamente, com despigmentação, eritema e crostas, sendo essas lesões localizadas em região dorsal do plano nasal e da pele (Banovic, 2019). A exposição solar agrava a doença em $50 \%$ dos casos, sendo sugerido que a fotossensibilidade desempenhe um papel importante na origem da doença (Hejazi \& Werth, 2016). Logo, a LED pode apresentar-se de forma mais grave no verão ou em áreas com climas ensolarados.

Embora seja a segunda doença mais frequente dentre as dermatopatias autoimunes, acredita-se que o número de casos verdadeiramente diagnosticados é menor que o real, uma vez que esta enfermidade apresenta um difícil diagnóstico (Gerhauser et al., 2006). Baseado nisso, o objetivo do presente trabalho é relatar a ocorrência de LED em cão atendido em uma clínica particular de Fortaleza.

\section{Relato de caso}

Um canino, macho, da raça Akita, com cinco anos de idade e $35,5 \mathrm{~kg}$, foi atendido no serviço especializado de dermatologia veterinária, apresentando prurido intenso e lesões crostosas em regiões periocular, nasal e membros. O cão apresentava histórico prévio de corticoterapia, a qual estabilizava as lesões cutâneas. Porém, quando a medicação era suspensa, o cão apresenta recidiva do quadro lesional. Mediante este quadro, houve necessidade de uma nova avaliação dermatológica em que foram observadas crostas, início de despigmentação em regiões laterais do focinho, discreta perda de arquitetura nasal, hiperemia e alopecia nas regiões de plano nasal e perioculares (Figura 1A), além de hiperqueratose escrotal (Figura 1B). Na avaliação clínica geral não foram encontradas outras alterações dignas de nota. $\mathrm{O}$ animal apresentava contactantes, os quais não apresentavam sintomatologia clínica.

Durante o primeiro atendimento foi realizada coleta de material de plano nasal para avaliação citológica, o qual evidenciou discreta quantidade de hemácias, células epiteliais descamativas, inflamatórias e debris celulares. Estas observações não sugeriram um diagnóstico conclusivo com relação à causa, mas teve importância no descarte de outras patologias. Foram ainda realizados hemograma completo e dosagens séricas de ureia, creatinina, albumina, globulina, glicemia, ALT e fosfatase alcalina), sorologia para Leishmaniose Canina (LCan), Erliquiose e Babesiose, além de ultrassonografia abdominal e biopsia cutânea. Previamente à realização da biopsia, os glicocorticoides foram suspensos durante 30 dias. Enquanto se 
esperava o resultado dos exames, foi prescrito o uso de pomada oftálmica (gentamicina e hidrocortisona) nas lesões perioculares, duas vezes ao dia, durante 10 dias consecutivos.

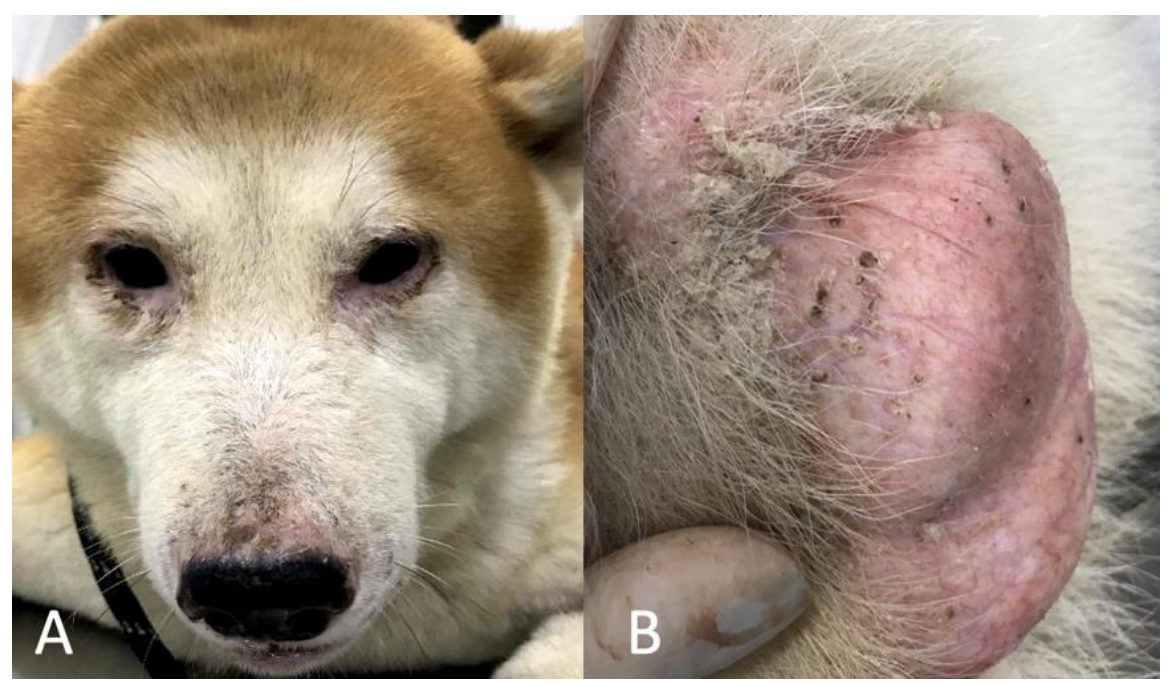

Figura 1. Aspectos dermatológicos em cão Akita com lupus eritematoso discoide. Lesões crostosas em região periocular (A) e plano nasal e hiperqueratose em saco escrotal (B).

Os exames hemato-bioquímicos encontravam-se dentro dos valores normais de referência para a espécie, com exceção da ALT e fosfatase alcalina (Tabela 1), as quais podem estar associados ao uso crônico de corticoide apresentado pelo paciente. Os testes sorológicos apresentaram resultados negativos. A histologia da região do focinho revelou dermatite de interface vacuolar e liquenóide (Figura 2). Vale ressaltar ausência de adeno, hepato e esplenomegalias e de alterações em sistemas locomotor e renal aos exames ultrassonográfico e clínico. Esses achados, associados à exclusão de outras enfermidades tegumentares e sistêmicas, sugerem a presença de LED.

Tabela 1. Parâmetros hematológicos e bioquímicos de cão Akita com lupus eritematoso discoide.

\begin{tabular}{lcc}
\hline Parâmetros & Valores & Referência: Meyer \& Harvey (2004) \\
\hline Hemácias $\left(\mathrm{x} 10^{6} / \mathrm{mm}^{3}\right)$ & 6,88 & $5,5-8,5$ \\
Hemoglobina $(\mathrm{g} / \mathrm{dL})$ & 13,9 & $12,0-18,0$ \\
Hematócrito $(\%)$ & 41,5 & $37-55$ \\
Leucócitos Totais $\left(/ \mathrm{mm}^{3}\right)$ & 6.300 & $6.000-18.000$ \\
Neutrófilos $\left(/ \mathrm{mm}^{3}\right)$ & 4.032 & $3.000-11.500$ \\
Linfócitos $\left(/ \mathrm{mm}^{3}\right)$ & 1.386 & $1.000-4.800$ \\
Ureia $(\mathrm{mg} / \mathrm{dL})$ & 26,0 & $15-65$ \\
Creatinina $(\mathrm{mg} / \mathrm{dL})$ & 0,8 & $0,5-1,5$ \\
ALT $(\mathrm{U} / \mathrm{I})$ & 462,0 & $10-88$ \\
Fosfatase Alcalina $(\mathrm{U} / \mathrm{I})$ & 275,0 & $20-150$ \\
Albumina $(\mathrm{g} / \mathrm{dL})$ & 3,3 & $2,6-4,0$ \\
Globulina $(\mathrm{g} / \mathrm{dL})$ & 3,0 & $2,7-4,4$ \\
Relação A/G & 1,1 & $0,5-1,7$ \\
Glicemia $(\mathrm{mg} / \mathrm{dL})$ & 99,0 & $60-110$ \\
\hline
\end{tabular}

Com os resultados da citologia e biopsia foi iniciado o tratamento para LED, a base de prednisolona oral na dose $2,2 \mathrm{mg} / \mathrm{kg} /$ dia durante 14 dias consecutivos, em seguida, na dose $1,1 \mathrm{mg} / \mathrm{kg} / \mathrm{dia}$, durante 14 dias consecutivos, em seguida $1,1 \mathrm{mg} / \mathrm{kg}$ a cada 48 horas por 14 dias consecutivos. Foi prescrito também o uso oral de pentoxifilina na dose de $23 \mathrm{mg} / \mathrm{kg} / \mathrm{dia}$, durante 30 dias consecutivos, além do uso oral de vitamina E (800 UI/dia). Foi recomendada também a aplicação tópica de furoato de mometasona no plano nasal a cada 12 horas, durante 30 dias consecutivos. 


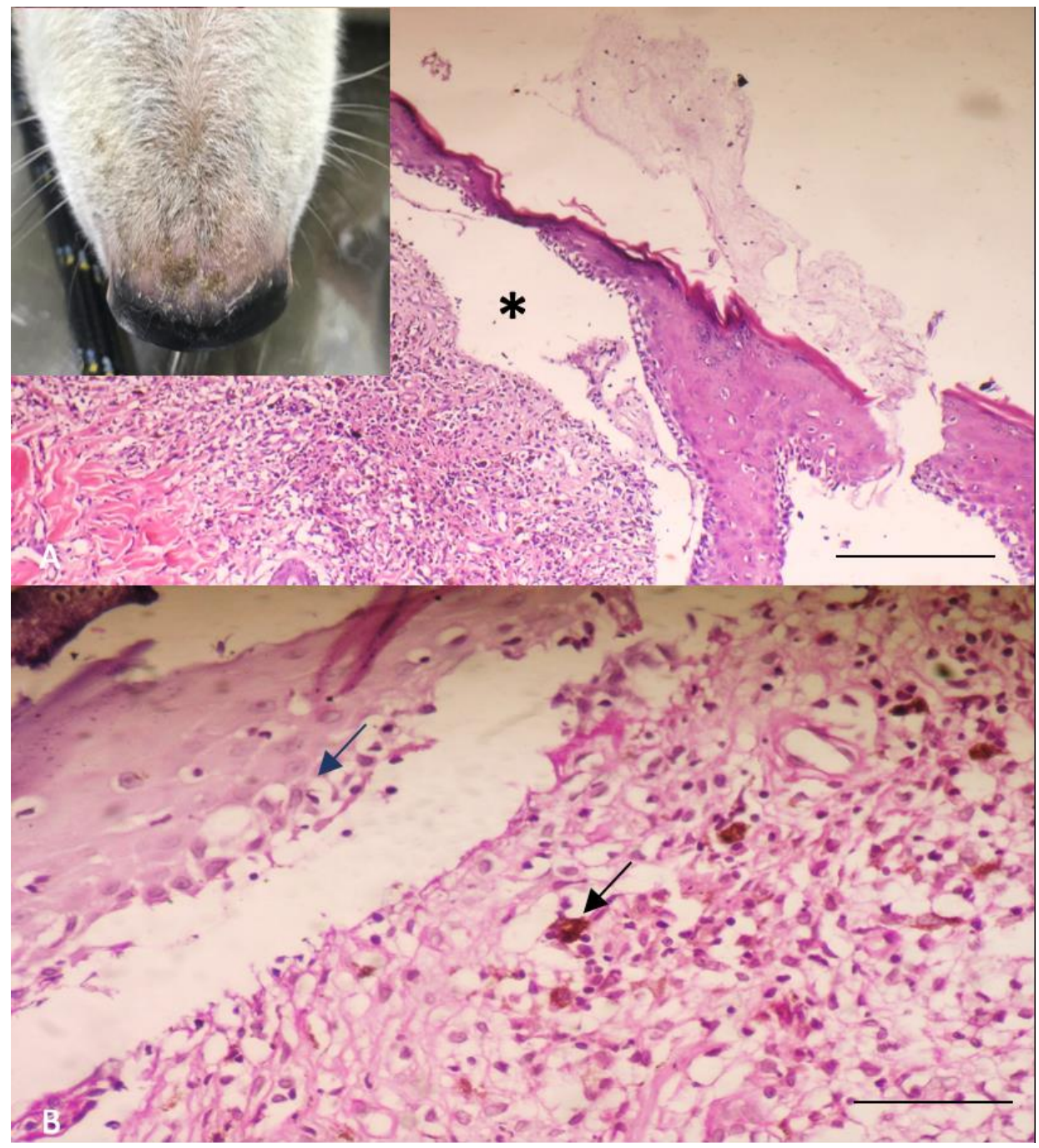

Figura 2. Padrões histopatológicos em cão com LED. (A) Dermatite de interface e liquenoide com presença de fenda (estrela) evidenciada na junção dermo-epidérmica em amplificação de 100x. (B) Vacuolização de células epidérmicas basais (seta azul) e incontinência pigmentar (seta preta) em amplificação de 400x. Coloração H\&E. Barra: $50 \mu \mathrm{m}$.

\section{Resultados e discussão}

O caso relata a ocorrência de lupus eritematoso discoide (LED) em cão da raça Akita. O LED é uma das afecções autoimunes mais comuns em cães, sendo descrita normalmente em cães dolicocefálicos, como Collies e Pastores de Shetland (Norris et al., 1997). O presente caso descreve a doença em um canino de raça Akita, a qual se assemelha aos dados previamente relatados, onde animais de raças puras, incluindo Akitas, são ditos como os mais acometidos (Palumbo et al., 2010).

O diagnóstico do cão foi realizado através do exame histopatológico, o qual revelou alterações dermo-epidérmicas (Figura 2), associado à exclusão de outras enfermidades cutâneas e sistêmicas. Na epiderme, destaca-se a presença de acantose, ortoqueratose, vacuolização de células basais, células apoptóticas e exocitose linfocítica. Esses achados estão comumente presentes na LED canina (Banovic, 2019), como consequência da imunopatogenia da doença, sendo ainda exacerbados na presença de radiações ultravioletas, as quais estão presentes em grande intensidade na cidade que o cão reside. Tais ondas (UVA e UVB) são capazes de penetrar na epiderme e atingir a camada basal, desencadeando diferentes mecanismos, incluindo apoptose celular, exposição de material nuclear e indução do processo inflamatório (Wolf et al., 2019). Além disso, o dano causado aos queratinócitos induz ao aumento da síntese de citocinas pró-inflamatórias e expressão de moléculas de adesão (Yu et al., 2013), justificando a exocitose presente na avaliação tecidual, caracterizando o processo inflamatório. 
A inflamação presente no LED canino acomete células basais, desestabilizando a zona da membrana basal (De Lucia et al., 2017). Esta camada tem por função a sustentação do tecido epidérmico e, quando lesionada, pode gerar uma fenda passível de visualização ao exame histopatológico (Figura 2A). É importante ressaltar que, por vezes, a fenda pode estar associada a erros de técnica histológica. Contudo, a presença de tal alteração associada ao quadro clínico do cão reforça o LED como diagnóstico diferencial (Banovic, 2019). O dano tecidual pode ainda deixar lacunas para a passagem de componentes da epiderme para a derme, como a melanina, resultando na incontinência pigmentar, a qual foi observada no paciente canino (Figura 2B). A progressão do processo inflamatório culmina com a desorganização e a disfunção das fibras colágenas, as quais são responsáveis pela manutenção da estrutura tecidual (De Lucia et al., 2017), o que a caracteriza como uma doença do colágeno. Logo, tais alterações se manifestam, clinicamente, através da despigmentação e perda da arquitetura nasal.

O LED é a forma clínica mais comum de lupus, representando, dentre as variantes lúpicas, a de menor risco para o desenvolvimento do Lupus Eritematoso Sistêmico (LES) (Larsson \& Lucas, 2019). Entretanto, quando há acometimento generalizado, o envolvimento cutâneo está presente em até $90 \%$ dos pacientes, sendo estes os primeiros sinais de LES em até 28\% dos casos (Hejazi \& Werth, 2016). Baseado nisso, foram realizados exames clínicos, hemato-bioquímicos e ultrassonográficos na intenção de descartar outras alterações no animal. Foi feito ainda diagnóstico diferencial para LCan devido à semelhança dos sinais dermatológicos, visto que alterações cutâneas como lesões alopécicas, hiperêmicas e a ocorrência de hiperqueratose em plano nasal são sinais comuns à LCan e LED (De Lucia et al., 2017). Além disso, o município de Fortaleza destaca-se como área endêmica para a doença, com alto número de casos humanos notificados, cães sororreagentes e flebotomíneos (Rodrigues et al., 2017). As avaliações realizadas estavam dentro dos parâmetros de normalidade para a espécie canina, o que reflete um quadro clínico restrito ao tegumento.

A terapia do paciente baseou-se no uso de imunomoduladores. Os casos de LED podem ser controlados com a utilização de corticoterapia tópica associada a tratamentos de suporte, como antiinflamatórios, vitamina E e protetor solar (Miller et al., 2013). O uso da pentoxifilina auxiliou no tratamento do animal, visto que essa droga possui atividade imunomodulatória por inibir a síntese de citocinas pró-inflamatórias (Larsson \& Lucas, 2019). O animal apresentou melhora significativa com o inicio do tratamento, reduzindo a hiperemia e a formação de crostas no plano nasal a partir de sete dias de terapia (Figura 3). Contudo, o cão continua em acompanhamento, sendo ainda recomendado o uso de protetor solar diariamente para evitar recidiva do quadro lesional.

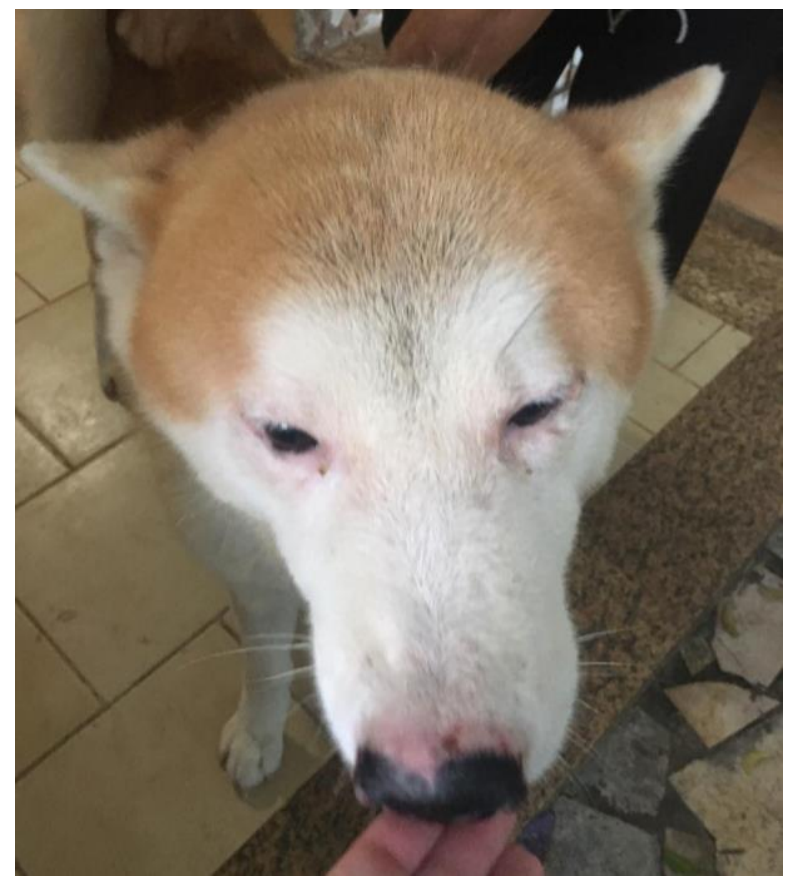

Figura 3. Aspecto dermatológico de focinho e região periocular após sete dias de terapia em cão com LED. 


\section{Conclusão}

O Lupus Eritematoso Discoide é uma enfermidade autoimune presente na rotina clínica de pequenos animais, exigindo do Médico Veterinário a atenção para os métodos diagnósticos e terapias adequadas de modo a fornecer melhor qualidade de vida ao paciente canino.

\section{Referências bibliográficas}

Banovic, F. (2019). Canine Cutaneous lupus erythematosus: Newly discovered variants. Veterinary Clinics: Small Animal Practice, 49(1):37-45.

De Lucia, M., Mezzalira, G., Bardagí, M., Fondevila, D. M., Fabbri, E. \& Fondati, A. (2017). A retrospective study comparing histopathological and immunopathological features of nasal planum dermatitis in $20 \mathrm{dogs}$ with discoid lupus erythematosus or leishmaniosis. Veterinary Dermatology, 28(2):200-e246.

Ferreira, T. C., Guedes, R. F. M., Bezerra, B. M. O. \& Nunes-Pinheiro, D. C. S. (2019). Mupirocin pemphigus-like drug reaction in a dog. Acta Scientiae Veterinariae, 471-6.

Gerhauser, I., Strothmann-Lverssen, A. \& Baumgorner, W. (2006). A case of interface perianal dermatitis in a dog: is this aunsual manifestation of lupus erythematosus? . Veterinary Pathology, 43(5):761-764.

Hejazi, E. Z. \& Werth, V. P. (2016). Cutaneous lupus erythematosus: an update on pathogenesis, diagnosis and treatment. American Journal of Clinical Dermatology, 17(2):135-146.

Larsson, C. E. \& Lucas, R. (2019). Tratado de medicina externa: dermatologia veterinária. São Caetano do Sul, São Paulo, Brasil: Interbook.

Meyer, D. J. \& Harvey, J. W. (2004). Veterinary laboratory medicine: interpretation \& diagnosis. Philadelphia, USA: Sauders.

Miller, W. H., Griffin, C. E., Campbell, K. L. \& Muller, G. H. (2013). Muller and Kirk's Small Animal Dermatology. Philadelphia, USA: Elsevier Health Sciences.

Norris, D. A., Bennion, S. D. \& David-Bajar, K. (1997). Pathomechanisms of cutaneous lupus erythematosus. Baltimore, USA: Williams \& Wilkins.

Palumbo, M. I. P., Machado, L. H. A., Conti, J. P., Oliveira, F. C. \& Rodrigues, J. C. (2010). Incidência das dermatopatias auto-imunes em cães e gatos e estudo retrospectivo de 40 casos de lupus eritematoso discóide atendidos no serviço de dermatologia da Faculdade de Medicina Veterinária e Zootecnia da UNESP-Botucatu. Semina: Ciências Agrárias, 31(3):739-743.

Pinho, R. M., Monzón, M. F. \& Simões, J. (2015). Dermatologia veterinária em animais de companhia.

Rodrigues, A. C. M., Melo, A. C. F. L., Júnior, A. D. S., Franco, S. O., Rondon, F. \& Bevilaqua, C. M. L. (2017). Epidemiologia da leishmaniose visceral no município de Fortaleza, Ceará. Pesquisa Veterinária Brasileira, 37(10):1119-1124.

Wang, L., Wang, F. S. \& Gershwin, M. E. (2015). Human autoimmune diseases: a comprehensive update. Journal of Internal Medicine, 278(4):369-395.

Wolf, S. J., Estadt, S. N., Theros, J., Moore, T., Ellis, J., Liu, J. \& Kahlenberg, J. M. (2019). Ultraviolet light induces increased $\mathrm{T}$ cell activation in lupus-prone mice via type I IFN-dependent inhibition of T regulatory cells. Journal of Autoimmunity, 103102291.

Yu, C., Chang, C. \& Zhang, J. (2013). Immunologic and genetic considerations of cutaneous lupus erythematosus: a comprehensive review. Journal of Autoimmunity, 4134-45.

Recebido: 29 de novembro, 2019.

Aprovado: 14 de janeiro, 2020.

Publicado: 29 de fevereiro, 2020 .

Licenciamento: Este artigo é publicado na modalidade Acesso Aberto sob a licença Creative Commons Atribuição 4.0 (CC-BY 4.0), a qual permite uso irrestrito, distribuição, reprodução em qualquer meio, desde que o autor e a fonte sejam devidamente creditados. 